\title{
EDITORIAL
}

\section{SOBRE LOS ALIMENTOS FUNCIONALES}

Pilar Farjas Abadía

Directora ejecutiva de la Agencia Española de Seguridad Alimentaria. Ministerio de Sanidad y Consumo. Madrid.

En algo menos de un siglo hemos asistido a numerosos y espectaculares avances en la historia de la humanidad. Algunos de ellos en terrenos tan importantes y esenciales como la alimentación, o deberíamos ya comenzar a hablar sobre nutrición, para lograr una diferenciación, un tanto artificial por cuanto las diferencias semánticas son mínimas, entre el mero hecho de consumo de alimentos para subsistir (alimentación) y el consumo de estos para lograr un acción reparadora, específica y adaptada a cada necesidad fisiológica. (nutrición).

Precisamente el recién finalizado siglo XX ha conocido una de las mayores paradojas en la situación alimentaria de la población de los países desarrollados. El contexto político y social que vivió Europa, asolada por dos Grandes Guerras, convirtió en crucial la necesidad de paliar la hambruna de la población. No preocupaban entonces ni la calidad ni la seguridad de los alimentos sino, mas bien, su disponibilidad y cantidad. Sin embargo, en el transcurso de un brevísimo espacio de tiempo no solo se superó esta situación sino que se invirtió, y la población de estas zonas del mundo se empezó a preocupar por lo que comía, en términos efectivos de exigir un mayor nivel de seguridad y calidad de los alimentos, hecho este muy ligado al desarrollo de las tecnologías de la información. Dentro de esta exigencia de calidad se enmarca la exigencia de una mayor información sobre la composición nutricional de los alimentos que se le ponen a su disposición.

Paralelamente hemos asistido a un imparable desarrollo de la industria alimentaria en su intento de seguir de cerca un mercado cada vez más globalizado y unas tendencias cambiantes en los alimentos que se consumen y en la forma en la que se consumen. La fortaleza económica del sector agroalimentario le ha permitido adaptarse perfectamente a cada uno de los contextos, muchas veces sin que esto conllevase un desarrollo sincrónico de las estructuras administrativas encargadas de su control. La industria alimentaria ha respondido a las demandas informativas de los consumidores sobre nutrición, bien a través de menciones en el etiquetado que recogen la composición nutricional del producto, o bien destacando en el etiquetado alguna cualidad nutricional en particular, todo ello acompañado de campañas publicitarias en un intento de diferenciar sus productos de sus competidores en el mercado. Lamentablemente, en algunos casos sin que esto estuviera avalado por estudios científicos solventes o confundiendo el criterio del consumidor.

Por otro lado, las estructuras administrativas, siempre imbuidas de una tremenda inercia, se adaptan difícilmente a las evoluciones $\mathrm{y}$, en ocasiones, han tardado mucho en dar las respuestas adecuadas, bien en forma de investigaciones y conclusiones ciertas sobre 
los beneficios de uno u otro alimento o nutriente o bien propiciando situaciones de desregularización que favorecen la proliferación indiscriminada de informaciones contradictorias en un terreno tan sensible para la población como su salud o hiperregulación que impiden o dificultan la incorporación de avances tecnológicos que pudieran resultar beneficiosos.

Los alimentos funcionales o enriquecidos han sido el foco de muchas discordias. La diversidad terminológica y conceptual se ve acompañada de una gran variedad de aportaciones científicas y pseudocientíficas y de un no menos variable criterio legislativo en el contexto mundial. Todo ello, sin duda, contribuye a crear un halo de confusión y de «prevención» justificada en la aceptación de este tipo de alimentos. Las finalidades sanitarias de algunos de estos productos suponen en algunos casos, como mínimo, un presunto fraude para los consumidores ya que no responden a una previa comprobación técnica o científica debidamente contrastada. Valga como ejemplo la confusión generalizada que existe entre el colesterol de la dieta y el colesterol sanguíneo. Mucha gente sabe que los huevos tiene un alto contenido en colesterol alimentario y asumen que suprimiendo los huevos de su dieta obtienen un efecto beneficioso sobre su nivel de colesterol sanguíneo, prescindiendo de uno de los alimentos más completos que se conocen.

En nuestro país existe una regulación que prohibe, entre otras, la utilización de cualquier mención que atribuya a determinadas formas, presentaciones o marcas de productos alimenticios de consumo ordinario, concretas y específicas propiedades preventivas, terapéuticas o curativas. Así mismo, la normativa europea relativa al etiquetado prohibe atribuir a cualquier producto alimenticio la propiedad de prevenir, tratar o curar enfermedades humanas, o hacer referencia a tales propiedades aunque se está estudiando la potencial incorporación a la legislación comunitaria de disposiciones específicas que rijan las «indicaciones funcionales»

La Unión Europea ha definido, como prioridad estratégica, una política de máxima protección de la salud de sus ciudadanos. Por ello la Comisión Europea se muestra enormemente sensible a los temas que, como la alimentación y la nutrición, son reconocidos como determinantes para la salud y el bienestar de los ciudadanos. En este sentido ha empleado esfuerzos en desarrollar tecnologías y métodos de fabricación encaminados a producir una alimentación segura, sana y variada, a fin de proteger a los consumidores y luchar contra las enfermedades ligadas a la alimentación, figurando la nutrición y alimentación como acciones claves sujetas a financiación en el marco de los programas específicos de investigación y desarrollo tecnológico.

Tenemos pues que admitir dos hechos incuestionables y absolutamente ligados entre sí: la esperanza de vida de la población en los países desarrollados se ha incrementado hasta valores inimaginables hace unos años y, por ello, es necesario que las estructuras sanitarias se ocupen de conseguir aumentar la calidad de vida en estos años y, por otra parte, la relación entre la nutrición y la salud, que hace que pensemos en la necesidad de profundizar en el conocimiento de cuales son los factores y elementos de la dieta que pueden contribuir a aumentar la calidad de vida, sobre todo en lo referente a la prevención de procesos crónicos.

Los organismos internacionales, como el Codex Alimentarius, realizan una labor de normalización y homogenización de los criterios que deben regir las políticas nacionales sobre todos los aspectos que inciden en la alimentación. Por ello deben reformular sus estrategias para introducir como prioridad el establecimiento de mecanismos de aceptación de la funcionalidad de determinados compuestos o elementos que forman parte de los alimentos o pueden hacerlo. En este sen- 
tido cabría la revisión de las posturas que este Organismo ha mantenido hasta la fecha de solo permitir la declaración de la utilidad de un alimento para prevenir, aliviar, tratar o curar una enfermedad, trastorno o estado fisiológico, en aquellos que cumplan las condiciones para regímenes especiales. Es cierto que sin una regulación adecuada y una estrategia global sobre dieta o nutrición óptima, existe el riesgo de inducir a un sobre consumo de determinados alimentos en detrimento de otros, cuyo papel en el mantenimiento de un correcto balance nutricional se considera esencial. Cada alimento tiene una función y no hay razones justificadas para crear una categoría especial de alimentos pero sí para controlar la información nutricional que se le proporciona a la población. El aspecto más relevante de esta cuestión es que sea la evidencia científica la que rija todo el proceso de información sobre la nutrición óptima, entendida como aquella que se adapta mejor a las necesidades de cada individuo. El proceso debe estar precedido por el consenso y desarrollado bajo reglas de juego consensuadas para evitar que los aluviones informativos a los que se somete a la población la confundan o induzcan a cometer errores. La elección informada y libre debe ser el objetivo y se deben tratar de superar las disputas comerciales que hasta ahora han sido las que gobiernan el proceso.

Vista toda esta situación, resulta necesario hacer esfuerzos mayores por conseguir integrar y enhebrar todos los aspectos que rodean a los alimentos funcionales, desde la investigación científica hasta la información que se proporcione al consumidor. La administración sanitaria, responsable de todos los aspectos de seguridad alimentaria y nutrición debe constituirse en catalizador de todos estos aspectos para conseguir la uniformidad en la información, la veracidad y transparencia que redunden en un beneficio claro para el avance de nuestra sociedad. La articulación de códigos de comportamiento ético de todas las partes implicadas podría ser un buen camino. A cambio, el compro- miso de potenciar la investigación científica y los estudios sobre nutrición, cuyos resultados se divulguen con plena transparencia, e implantar políticas nutricionales efectivas, basadas en el uso de herramientas de información adecuadas que permitan una elección libre y, a ser posible, correcta, y mejorar los procedimientos de puesta en mercado de forma que se le garantice una amplia disponibilidad para ejercer su derecho a una dieta sana y equilibrada.

En este sentido, quiero señalar la oportunidad del artículo elaborado por el personal del Servicio de Endocrinología y Nutrición del Hospital Universitario de Getafe. En un contexto de indefinición, conceptual y normativa, a nivel internacional, en la que existen normas que se solapan, a veces contradicen, o incluso dejan huecos por donde caben situaciones que perjudican claramente los derechos a la protección de la salud de los ciudadanos; y en un clima de diferenciación competitiva de los productos en el mercado en base al marketing de supuestos beneficios para la salud de los consumidores, convirtiendo a los alimentos en poco menos que medicamentos, este tipo de artículos, sin duda puede contribuir a poner un poco más en claro la información actual disponible y coincide con los esfuerzos que está realizando la Agencia Española de Seguridad Alimentaria (AESA), tanto en la elaboración de normas regulatorias, como en el control de los productos y de la información que contienen.

Por todo ello desde la AESA compartimos absolutamente todas las conclusiones que se derivan del mismo y entendemos que este es uno de los temas en los que tendremos que ocupar nuestra atención en los próximos años.

\section{BIBLIOGRAFÍA}

1. Etiquetado de los Alimentos - Textos completos . Comisión Mixta FAO/OMS del Codex Alimentarius; 2001. 
2. Decisión 1999/167/CE del Consejo, de 25 de enero de 1999, por la que se aprueba un programa específico de investigación, desarrollo tecnológico y demostración sobre «Calidad de la vida y gestión de los recursos vivos» (1998-2002). Diario Oficial L 64 de 12.03.1999.

3. Alimentos sanos para los ciudadanos europeos. La Unión Europea y la calidad de los alimentos Comisión Europea. Dirección General de Educación y Cultura División «Publicaciones», rue de la Loi 200, B-1049 Bruselas: Unión Europea; 2000.
4. Libro blanco sobre seguridad alimentaria. Bruselas: Unión Europea; 1999.

5. Reglamento $\mathrm{n}^{\circ}$ 258/97 del Parlamento Europeo y del Consejo de 27 de enero de 1997 sobre nuevos alimentos y nuevos ingredientes alimentarios. Diario Oficial núm L 043 de 14/02/1997 p. 0001 0006 .

6. Real Decreto 1907/96 de 2 de agosto, sobre publicidad y promoción comercial de productos, actividades o servicios con pretendida finalidad sanitaria. BOE núm: 189/1996 del 06-08-1996. 